\title{
Editorial: Future Oceans Under Multiple Stressors: From Global Change to Anthropogenic Impact
}

\author{
Erik Olsen ${ }^{1 *}$, Isaac C. Kaplan ${ }^{2}$, Cecilie Hansen ${ }^{1}$, Elizabeth Fulton ${ }^{3,4}$, Michael J. Fogarty ${ }^{5}$, \\ Jamie C. Tam ${ }^{6}$ and Saskia A. Otto ${ }^{7}$ \\ ${ }^{1}$ Norwegian Institute of Marine Research (IMR), Bergen, Norway, ${ }^{2}$ Northwest Fisheries Science Center (NOAA), Seattle, WA, \\ United States, ${ }^{3}$ Center for Marine Socioecology, University of Tasmania, Hobart, TAS, Australia, ${ }^{4}$ CSIRO Oceans \& \\ Atmosphere, Hobart, TAS, Australia, ${ }^{5}$ Northeast Fisheries Science Center (NOAA), Woods Hole, MA, United States, \\ ${ }^{6}$ Bedford Institute of Oceanography, Dartmouth, NS, Canada, ${ }^{7}$ Center for Earth System Research and Sustainability, Institute \\ of Marine Ecosystem and Fishery Science, University of Hamburg, Hamburg, Germany
}

Keywords: models and modeling, indicators, cumulative impacts, climate change, fisheries

\section{Editorial on the Research Topic}

Future Oceans Under Multiple Stressors: From Global Change to Anthropogenic Impact

\section{INTRODUCTION}

If humanity is to achieve the ambitious targets of the UN Sustainable Development Goals (UN, 2015), we need assessments of future scenarios that evaluate combinations of natural and anthropogenic drivers that exert stress to the system as well as management actions. The current

OPEN ACCESS

Edited and reviewed by: Susana Agusti,

King Abdullah University of Science and Technology, Saudi Arabia

*Correspondence:

Erik Olsen

eriko@hino

Specialty section:

This article was submitted to Global Change and the Future Ocean,

a section of the journal

Frontiers in Marine Science

Received: 15 September 2020 Accepted: 29 September 2020 Published: 04 November 2020

Citation:

Olsen E, Kaplan IC, Hansen C, Fulton E, Fogarty MJ, Tam JC and

Otto SA (2020) Editorial: Future

Oceans Under Multiple Stressors:

From Global Change to

Anthropogenic Impact.

Front. Mar. Sci. 7:606538.

doi: 10.3389/fmars.2020.606538
Research Topic explores futures for our oceans and coastal areas with a strong focus on effects of climate change, but also covering fishing, mass mortality events, and cumulative impacts from multiple stressors and human activities. It provides future visions for different timescales and regions, and what can be done to ameliorate negative impacts or outcomes.

The geographic scope covers regions from the coast and enclosed seas to the open oceans, and from the Arctic to Southern Ocean. Together these 20 articles paint a stark picture of the changes expected in our oceans but also present assessment methods, management paths, policies, and actions necessary to alleviate and deal with future problems.

\section{CLIMATE CHANGE AND FISHERIES}

This Research Topic demonstrates that fisheries and climate still dominate thinking around ocean stressors. The relative impact of fishing vs. climate, and the extent to which improved fisheries management and conscious decisions about technological progress can ameliorate climate impacts (Galbraith et al., 2017) is likely to be of increasing importance in the future. For the pelagic Central North Pacific Ocean, Woodworth-Jefcoats et al. apply multi-species size-spectrum models to understand the impacts of climate scenarios on the ecosystem and fisheries. Here, climate change led to reductions in forage species and long-term declines in fisheries, though limits to fishing effort could partially offset these outcomes. Reum et al. apply a similar size-spectrum model to the Eastern Bering Sea (EBS). They noted long-term declines in ecosystem and fishery metrics. However, analysis of varying fishing rates suggested less scope for compensation or amelioration by fisheries management. Notably, the fisheries management scenarios for the EBS involved relatively small (and perhaps politically realistic) adjustments to status quo, while the central North Pacific fishery scenarios included large (50 and $80 \%$ ) reductions in fishing effort. These modeling efforts are part of the Alaska Climate Integrated Modeling (ACLIM) project, which aims to analyze and 
model the current and future climate driven changes to the EBS socio-economic system (Hollowed et al.).

Hansen et al. and Tunca et al. examine similar scenarios of varying fishing (pressure) under climate change for the Nordic and Baltic seas, respectively, using an end-to-end ecosystem model of the Nordic seas and a coupled bio-economic model for the Baltic. For both regions, ecosystem vulnerability to climate-change increased with increasing fishing, especially when expanding the fisheries to lower trophic levels (Hansen et al.), or for non-cooperative fisheries scenarios (Tunca et al.). In the Mediterranean, Moullec et al. use coupled modeling to project climate change scenarios on fish stocks and fisheries, showing an overall increase in fish biomass and catches but with large regional differences.

Downscaling of climate change effects has been shown to be important in evaluating species-specific effects. Sandø et al. projected a northward shift in spawning sites for Northeast Arctic cod, and Greenan et al. found overall positive effects on lobster habitat in the Gulf of Maine with increasing temperature, although the population is expected to shift toward the northeast, with associated socioeconomic impacts. In the Arctic, downscaled climate effects on benthic habitats were shown to be limited when evaluated for all taxonomic groups, but suitable habitat for $18 \%$ of the taxa studies were projected to change by more than $20 \%$, suggesting serious ecological impact (Renaud et al.).

\section{CUMULATIVE IMPACTS AND MULTIPLE STRESSORS}

Climate change effects need to be evaluated in conjunction with other pressures and drivers which exert stress and impair the functioning of the ecosystem (as discussed in Davies et al.). Assessing such multiple stressors and cumulative impacts is key to understanding our future oceans. Weijerman et al., illustrate one example in a model of the Mau Nui region of Hawaii. There, coral reef systems were influenced not only by fishing and climate (bleaching) but also by nutrification, sediment, and local wave action, and local management had a strong influence on performance in terms of ecosystem services. Using a statistical modeling framework, Otto et al. explore the long-term effects of cumulative impacts on a key zooplankton species in the Baltic, showing that multiple pressures were mostly additive, but that the population effects were dampened through density dependence. Consideration of cumulative effects suggests that while many multiple stressor interactions may be additive (Crain et al., 2008; Brown et al., 2013; Otto et al.), negative synergistic and positive dampening effects can lead to lower than expected outcomes (if we were assuming additive interactions). Beauchesne et al. investigate additive cumulative impacts from multiple stressors at an ecosystem level for the St. Lawrence system. They classified the cumulative impacts into six clusters depending on their relative levels within the climate, coastal, fisheries, and marine traffic drivers, with the highest exposure hotspots identified at the head of the Laurentian channel.

\section{TOPICAL EFFECTS OF CLIMATE CHANGE AND OTHER PRESSURES}

Not all responses to climate change or other pressures and drivers are necessarily negative or linear, and topical studies exploring the effects on key trophic groups or key processes are in high demand. Andrew et al. provide vital insights into how iron availability is key for Southern Ocean phytoplankton to tolerate higher temperatures, while Gao et al. review the effects of ocean acidification (OA) on algae under multiple stressors. Responses can be highly variable, but for most calcifying algae, the combined effects of OA, UV, and increased temperatures reduce their growth. There is also need for topical knowledge of biological stressors, such as mass mortality events (MMEs) caused by pollution, natural disasters, or diseases. Olsen et al. look into the effect of MMEs on the Nordic seas using an end-toend ecosystem model, showing immediate and long-term direct and indirect effects, including potential hysteresis (Sguotti et al., 2019) that should be taken as caution when managing activities that can potentially cause MMEs. Fisheries also have nuanced effects on marine ecosystems, and detailed consideration of various management options is necessary to devise sustainable management strategies for the future. Balanced harvesting $(\mathrm{BH})$ is one such alternative fisheries strategy. Nilsen et al. explore the effects of BH on the Nordic seas using an end-to-end ecosystem model, showing that for well-managed stocks, the effects were marginal, while for lower trophic level species, a BH strategy would have broadened the mix of species exploited and produce higher yields.

\section{INDICATORS AND ECOSYSTEM MODELS}

The complexity of the socioecological marine systems and the cumulative impacts on these systems challenges us to synthesize our analytical results. Indicators of ecosystem state and the system's socio-economy (e.g., fisheries catches and revenues) have become standard in the EBM toolbox. Still, indicators need to capture trophic interactions, detect changes, and be consistent, transparent, comparable, and understandable. Designing indicators that meet these goals is difficult and should incorporate rigorous statistical testing comparable to what Kadin et al. carried out for trophic indicators of the Baltic ecosystem, where both thresholds and non-linear effects on indicators were evaluated. Measuring either the ecosystem or socioeconomic responses is not enough, however, as Fay et al. showed how ecosystem and fisheries indicators have different responses to the same fisheries management scenarios in the Northeast US. Due to the complexity and also utility of end-to-end models in EBM Tam et al. argue that indicators should be integrated into the modeling process, not estimated post-hoc as has been the typical approach.

\section{MANAGEMENT AND STAKEHOLDERS}

Effective governance and management are necessities to deal with the challenges of the future oceans, but it has proven difficult to move from a fragmented sectoral system to an 
integrated management approach that addresses the complexities of cumulative impacts and multiple sectors in an adequate manner (Davies et al.). Creating a unified vision for comanagement and inclusion of indigenous rights and place-based understanding of the ecosystem knowledge are key factors to achieve holistic and effective cumulative-effects management of the Aotearoa area (New Zealand) and Great Barrier Reef Marine Park (Davies et al.). The importance of localized management is further supported by the spatial modeling of local management scenarios for the Maui Nui area in Hawai'i, where local sediment control was critical in slowing coral reef decline under climate change (Weijerman et al.). Due to existing management policies, socio-economic and political status the path to achieving an integrated management approach will look different for each country. However, the elements of robust science, public, and political support are essential elements.

\section{DISCUSSION}

In the future, substantial (often negative) changes to our marine ecosystems are expected. However, the story is far from simple. Changes will not necessarily be negative for all species or habitats. Moreover, many of the combined effects are either dampened or synergistic, and may in some cases (Olsen et al.; Kadin et al.) show signs of hysteresis (Sguotti et al., 2019). Regionalized management options, tailor-made to the particular socioeconomic system, are overall to be recommended-be it in the design of indicators, downscaling of models or development of management and policy including local stakeholders and indigenous groups. In particular, a number of the papers in this Research Topic stress the importance of downscaling global model results (e.g., climate models) to address regional and local issues, ecosystem components, and drivers (Reum et al.; Hollowed et al.; Moullec et al.; Sandø et al.), as well as the diversity of responses (Andrew et al.). This means that while we may be forced to examine aggregated outcomes due to scarcity of data, where we can gain species-specific knowledge of system responses it will help identify the true differential outcomes across species (Renaud et al.).

The articles in this Research Topic advance and apply scenarios in various ways, ranging from relatively simple

\section{REFERENCES}

Brown, C. J., Saunders, M. I., Possingham, H. P., and Richardson, A. J. (2013). Managing for interactions between local and global stressors of ecosystems. PLoS ONE 8:e65765. doi: 10.1371/journal.pone.00 65765

Crain, C. M., Kroeker, K., and Halpern, B. S. (2008). Interactive and cumulative effects of multiple human stressors in marine systems. Ecol. Lett. 11, 1304-1315. doi: 10.1111/j.1461-0248.2008.01253.x

Galbraith, E. D., Carozza, D. A., and Bianchi, D. (2017). A coupled humanEarth model perspective on long-term trends in the global marine fishery. Nat. Commun, 8, 1-7. doi: 10.1038/ncomms14884

Holsman, K., Samhouri, J., Cook, G., Hazen, E., Olsen, E., Dillard, M., et al. (2017). An ecosystem-based approach to marine risk assessment. Ecosyst. Health Sustain. 3:e1256. doi: 10.1002/ehs2.1256 manipulations of fishing rates (Hansen et al.; Fay et al.; Kadin et al.; Woodworth-Jefcoats et al.; and others in this issue), to development of complete policy-relevant scenarios for the Eastern Bering Sea and Hawaii (Hollowed et al.; Reum et al.; Weijerman et al.). Applying game theory models to the Baltic Sea multi-species fishing fleets, Tunca et al. illustrate the high degree to which performance of future management scenarios hinges on the level of cooperation among fishing nations. However, for the most part these consider only local or regional socio-economic and fishery drivers. Moving forward, there is a need to develop and customize the global or "broad-brush" scenarios such as the Shared Socioeconomic Pathways (SSPs) (Maury et al., 2017; O'Neill et al., 2017; Riahi et al., 2017) at a local or regional level. Application of a common set of global scenarios will also aid comparisons across ecosystems (Olsen et al., 2018; Lotze et al., 2019).

This Research Topic illustrates two transdisciplinary connections that must be made to better understand and model future ocean ecosystems. First, modeling of marine living resources should embrace cutting edge understanding regarding biogeochemical modeling and global drivers of primary production. Articles in this issue by Gao et al. and Andrew et al. illustrate the important roles of UV, iron, trace metals, stress or interactions, and responses that vary across species and broader taxa of primary producers. These responses underpin the assumptions and predictions necessary to forecast provisioning of marine ecosystem services for humanity. Second, envisioning our future oceans requires transdisciplinarity (Yates et al., 2015) including improved socio-ecological models and integrated ecosystem assessments (Holsman et al., 2017), together with better integration of stakeholders and indigenous groups (Davies et al.). This will be facilitated by transparent and easy access to data and information, for which integrated information sharing systems like eDrivers (Beauchesne et al.) are recommended.

\section{AUTHOR CONTRIBUTIONS}

All authors listed have made a substantial, direct and intellectual contribution to the work, and approved it for publication.
Lotze, H. K., Tittensor, D. P., Bryndum-Buchholz, A., Eddy, T. D., Cheung, W. W., Galbraith, E. D., et al. (2019). Global ensemble projections reveal trophic amplification of ocean biomass declines with climate change. Proc. Natl. Acad. Sci. U.S.A. 116, 12907-12912. doi: 10.1073/pnas.1900194116

Maury, O., Campling, L., Arrizabalaga, H., Aumont, O., Bopp, L., Merino, G., et al. (2017). From shared socio-economic pathways (SSPs) to oceanic system pathways (OSPs): Building policy-relevant scenarios for global oceanic ecosystems and fisheries. Global Environ. Change 45, 203-216. doi: 10.1016/j.gloenvcha.2017.06.007

Olsen, E., Kaplan, I. C., Ainsworth, C., Fay, G., Gaichas, S., Gamble, R., et al. (2018). Ocean futures under ocean acidification, marine protection, and changing fishing pressures explored using a worldwide suite of ecosystem models. Front. Mar. Sci. 5:64. doi: 10.3389/fmars.2018.00064

O’Neill, B. C., Kriegler, E., Ebi, K. L., Kemp-Benedict, E., Riahi, K., Rothman, D. S., et al. (2017). The roads ahead: Narratives for shared socioeconomic 
pathways describing world futures in the 21st century. Global Environ. Change 42, 169-180. doi: 10.1016/j.gloenvcha.2015.01.004

Riahi, K., Van Vuuren, D. P., Kriegler, E., Edmonds, J., O’Neill, B. C., Fujimori, S., et al. (2017). The shared socioeconomic pathways and their energy, land use, and greenhouse gas emissions implications: an overview. Global Environ. Change 42, 153-168. doi: 10.1016/j.gloenvcha.2016. 05.009

Sguotti, C., Otto, S. A., Frelat, R., Langbehn, T. J., Ryberg, M. P., Lindegren, M., et al. (2019). Catastrophic dynamics limit Atlantic cod recovery. Proc. R. Soc. B 286:20182877. doi: 10.1098/rspb.201 8.2877

UN (2015). United Nations General Assembly: Transforming Our World: The 2030 Agenda for Sustainable Development. Draft Resolution Referred to the United Nations Summit for the Adoption of the post-2015 Development Agenda by the General Assembly at its Sixty-Ninth Session. UN Doc. A/70/L.1 of 18 September 2015.
Yates, K. K., Turley, C., Hopkinson, B. M., Todgham, A. E., Cross, J. N., Greening, H..., and Johnson, Z. (2015). Transdisciplinary science a path to understanding the interactions among ocean acidification, ecosystems, and society. Oceanography 28, 212-225. doi: 10.5670/oceanog.2015.43

Conflict of Interest: The authors declare that the research was conducted in the absence of any commercial or financial relationships that could be construed as a potential conflict of interest.

Copyright $\odot 2020$ Olsen, Kaplan, Hansen, Fulton, Fogarty, Tam and Otto. This is an open-access article distributed under the terms of the Creative Commons Attribution License (CC BY). The use, distribution or reproduction in other forums is permitted, provided the original author(s) and the copyright owner(s) are credited and that the original publication in this journal is cited, in accordance with accepted academic practice. No use, distribution or reproduction is permitted which does not comply with these terms. 